\title{
Rastin Certificate Market (RCM):A Complementary System of Rastin Banking
}

\author{
Bijan Bidabad \\ B.A., M.Sc., Ph.D., Post-Doc. \\ Professor \\ Economics and Chief Islamic Banking Advisor \\ Bank Melli, Iran \\ E-mail:bijan@bidabad.com
}

\begin{abstract}
New financial instruments as Rastin Certificates and Rastin Swap Bonds are used in Rastin banking. Rastin Certificate Market (RCM) provides necessary conditions for transaction and transfer of these instruments based on information technology and the integrated Rastin banking subsystems. This market is accessible for electronic account holders on the World Wide Web.
\end{abstract}

Keywords: Islamic Banking, Rastin Banking, Rastin Profit and Loss Sharing, Electronic Transaction,Rastin Certificate, Over the Counter Market, Secondary Market

\section{Introduction}

Web-based Over the Counter (OTC) software is extensively used as transaction markets for financial papers and derivatives at the present time. Financial intermediation between borrowers and lenders as a web-based commercial approach has found its own ground in financial markets. For example, in Zopa ${ }^{1}$ method, lender supplies the fund and borrower obtains his loan through Zopa Company. Most of these activities take place through online webs, and transactions are settled online. Of course, marginal problems created through collaterals and guarantees for observing obligations in larger loans or obligations created through derivatives lead to inefficiency of these systems. In addition to removal of this defect, Rastin banking ${ }^{2}$ is a framework for true Islamic banking that not only removes the prevailing difficulties but also increases the efficiency of banks in extending financial intermediation by applying new financial instruments such as Rastin Certificates and Rastin Swap Bonds. The web-based Rastin Certificate Market is established and administered by the agent bank and is used for the transaction of various Rastin Certificates and Rastin Swap Bonds. Rasin Certificate Market practically provides an electronic subsystem for the transaction of these digital papers in the framework of Rastin banking activities. This market works as both primary and secondary markets. This system has been installed in Bank Melli $\operatorname{Iran}^{3}$.

\section{Rastin PLS Banking}

In Rastin PLS banking as the main subsection of Rastin Banking, on behalf of the depositor, the bank finances entrepreneur for investment according to compiled regulations, and at the end project, the entrepreneur will distribute the profit/loss of the project in proportion to capital and duration of using that capital with the depositor. ${ }^{4}$ Rastin PLS Base system refers to the main process and general regulations of Rastin Profit and Loss Sharing (PLS) Banking system. On request and on behalf of the depositor, the bank invests his fund in one of Rastin PLS products and instead, gives Rastin Certificate of the selected project to him and allocates his fund to the selected project of the entrepreneur; and supervises the implementation and execution of the project. In the end, after deducting its own commission, bank divides the profit/loss (if any) among engaged sides (depositors and entrepreneur). The bank is the agent of the depositor and is responsible for observing his rights (depositor). He must use all his expertise to reach this end.

The fixed profit rate is eliminated in Rastin PLS banking, and the return rate is calculated according to the real return of capital in the real economy. Most of the regulations of Rastin PLS Base system are extended to its financial

\footnotetext{
${ }^{1}$ http://uk.zopa.com/

${ }^{2}$ Rastin banking documents are accessible at: http://www.bidabad.com

${ }^{3}$ http://pls.bmi.ir/

${ }^{4}$ Bidabad, Bijan, General Characteristics of Rastin Banking, 2013. http://www.bidabad.com/doc/rastin-bank-general-en.pdf
} 
subsystems. This system has its own organization, structure, and working process.

Rastin PLS financial subsystems refer to specific financing methods or services in Rastin PLS Banking. These subsystems work under general regulations of Rastin PLS Base system. ${ }^{5}$

\section{Rastin Certificates}

Rastin Certificates are a collection of designed certificates in Rastin PLS Banking Base system and its financial subsystems. These certificates can be anonymous or named papers, which are transferable and negotiable online through the website of the bank and are issued with a nominal price and for a certain period. The owners of these certificates share the results of the project proportional to nominal price and participation period of the certificate. Various Rastin Certificates and their characteristics according to the kind of participation in the PLS Base system or its financial subsystems regarding the type of project and the asset used as:

- $\quad$ PLS Base: Musharakah (Participation) and Pazireh (Subscripted) Certificates. ${ }^{6}$

- JFS: Future Certificate. ${ }^{7}$

- $\quad$ MFS: Mudarabah and Periodic Mudarabah Certificates. ${ }^{8}$

- IFS: Ordinary Mughasatah (installment), Rental Mughasatah, and Musharakah Mughasatah Certificates. ${ }^{9}$

- RFS: Mortgage Sharing, Periodic Mortgage Sharing, Mortgage Mudarabah (commerce), Periodic Mortgage Mudarabah, Mortgage Muzaraah (cultivating), Periodic Muzaraah, Mortgage Mugharasah (planting), Periodic Mortgage Mugharasah, Mortgage Musaghah (irrigation), Periodic Mortgage Musaghah, Mortgage Istisna (industrial/manufacturing), Periodic Mortgage Istisna and Rental Certificates. $^{10}$

- BFS: Bail Certificate. ${ }^{11}$

- RPS: Social Security, Personal Security, and Pension Security Certificates. ${ }^{12}$

- RST: Takaful and Loan Certificates. ${ }^{13}$

\section{Rastin Swap Bond (RSB)}

Rastin Swap Bond (RSB) is based upon Mubadala (swap) contract between Mobadil (swapper) and Motebadil (swapee) in which the durations and substances of swaps are equal for first and second swaps. Motebadil (swapee) issues the bond and owes to Mobadil equal to the nominal value of the bond, and should pay this amount (badal) to

\footnotetext{
${ }^{5}$ Bidabad, Bijan, Rastin Profit and Loss Sharing (PLS) Base System, 2012. http://www.bidabad.com/doc/pls-base-en.pdf

${ }^{6}$ Bidabad, Bijan, Rastin Profit and Loss Sharing (PLS) Base System, 2012. http://www.bidabad.com/doc/pls-base-en.pdf

${ }^{7}$ Joalah Financial Sharing (JFS): is a method in which, bank finances entrepreneur (producer) from depositor's resources or the provided sources by buyer.

Bidabad, Bijan, Joalah Finance Sharing (JFS), 2011. http://www.bidabad.com/doc/jfs-paper-en.pdf

${ }^{8}$ Mudarabah Financial Sharing (MFS): is a kind of mudarabah under Rastin PLS banking in which bank introduces the entrepreneur project proposal in the field of trade or transaction of commodities (commerce) to depositors.

Bidabad, Bijan, Mudarabah Financial Sharing (MFS). 2011. http://www.bidabad.com/doc/mfs-paper-en.pdf

${ }^{9}$ Installment Financial Sharing (IFS): in IFS, installer (depositor) will finance a portion of the needed fund of entrepreneur through the bank for a certain period of time (amortization period). The entrepreneur will pay back his share by installments and will own the total property of the project and IFS ends.

Bidabad, Bijan, Installment Financial Sharing (IFS), 2011. http://www.bidabad.com/doc/ifs-paper-en.pdf

${ }^{10}$ Rent Financial Sharing (RFS): entrepreneur temporarily donates the ownership of a part of his productive asset (assets of an operating firm), rental asset (those assets, which can be let) or dead asset (non-operating or suspended firms or uncultivated lands assets) to depositor who finances him but keeps it as mortgage. Then pays back the fund received from the yields of the asset proportional to depositor's share to depositor at the end of contract, or periodically. The original deposit of depositor will be given back to him after the end of project. The profit of the project will be given to depositor periodically or in a lump.

Bidabad, Bijan, Rent Financial Sharing (RFS), 2012. http://www.bidabad.com/doc/rfs-paper-en.pdf

${ }^{11}$ Bail Financial Sharing (BFS): is the application of deposit of depositor by entrepreneur to produce a defined commodity and delivering the commodity or paying back its value in future specific time.

Bidabad, Bijan, Bail Financial Sharing (BFS), 2012. http://www.bidabad.com/doc/bfs-paper-en.pdf

${ }^{12}$ Rastin Personal Security (RPS): to create competitive conditions and to increase the efficiency of social security insurance and diminishing antitrust of social security systems and pension funds, private and public pension funds are established according to Rastin Banking regulations. People and firms can allocate a portion of their obligatory (or optional) insurance premium payments (for himself or his employees) for social security to the funds that operate under Rastin Personal Security (RPS) and enjoy its benefits. Therefore, they will be exempted from obligatory insurance premium payments equal to the payment they have paid to these funds.

Bidabad, Bijan, Rastin Personal Security (RPS), 2012. http://www.bidabad.com/doc/rps-paper-en.pdf

${ }^{13}$ Rastin Social Takaful (RST): benevolent people can deposit their funds at banks for charity purposes, and bank will be allowed to pay profit (or the principal as well) of deposit to needy people, in form of loan or non-returnable payments (according to the depositor request).

Bidabad, Bijan, Rastin Social Takaful (RST), 2012. http://www.bidabad.com/doc/rst-paper-en.pdf
} 
Mobadil (swapper) at maturity. The issuer (Motebadil) is obliged to give the mobaadal for the same amount and period as badal to mobadil. He can choose a combination of amount and period that the multiplication of amount by the period of mobaddal be equal to that of badal. At second maturity, mobadil is committed to returning mobaddal to motebadil.

No interest rate is involved in these bonds, and they are of four kinds: Central Bank Rastin Swap Bond, Treasury Rastin Swap Bond, Bank Rastin Swap Bond, and Commercial Rastin Swap Bond. They can be in domestic money or foreign exchange. ${ }^{14}$

\section{Operational Flow in Rastin Certificate Market}

Generally, Rastin Certificate Market has the following sections:

- Information Portal: Information about Rastin Certificates and Rastin Swap Bonds are presented in this section. The information includes the number and latest transaction prices and also PLS branch information such as balance sheet, profit and loss report and the other financial report of the branch to be offered to the clients. Introduction to the application of the portal and membership procedure of the portal are also explained in this section. The portal has the duty of information unit in Rastin PLS branches, and therefore, it has vast and various topics so that it can respond to most of the clients' questions about Rastin PLS banking system.

- Registration and Membership: To enter and use various services (such as transaction or transfer) of the portal, the client should fill the related forms. Those clients who want to use both selling and buying services of the portal, in addition to confirming their (electronic) signature and observing regulations concerning electronic transaction of Rastin Certificate or Rastin Swap Bond, should open a deposit account with a cash deposit equal to the amount of their purchase and its commission. After filling the form and entering and uploading the necessary information, the client will receive a unique identification code. After entering into the electronic Rastin Certificate transaction site, the client will be directed to registration and membership page, and the client enters his code and electronic mailing address. Then, his username and password will be emailed to him.

- Buy/Sell Bid: To offer a purchasing bid, the client will enter his username and password and after confirming the regulations concerning purchase/sell and commission, will be allowed to enter into this section and see the latest information about certificates conditions including products and latest price offers made. If he is inclined to buy any of the certificates, he can include it in his purchasing basket by a click. After selecting the item, the client should propose a new price. In order to accept and register the client's proposed price (bid), the proposal should be higher than the latest proposed price. In order to persuade competition between the clients, the portal will email the latest information about proposals (including the highest proposal and the highest amount proposed to buy) on the project offered for sale to the clients. The amount of purchase of each client and its commission should not be more than the available amount of client account. If his account position is not enough for the purchase, he will receive a message to drop some items from his purchasing basket.

After confirmation, a copy of his proposal will be sent to the client's outbox. Client's account will be blocked for the amount of his purchase plus its commission while his proposal has the highest priority. By receiving the client's proposal, the computer database will be updated. Blocking and unblocking the client's account will be emailed to his inbox.

Also in the case of offering some certificate for sale, the client has to enter his username and password similar to purchasing case, and after confirming the conditions and regulations concerning electronic transaction of Rastin Certificates or Rastin Swap Bonds, he will obtain entrance permission to the site, and then will fill his offer in related form. Sale duration is predefined and specified. The period considered by the portal is 24 working hours according to Tehran time zone. The client is allowed to increase his sale duration up to 15 days.

It is necessary to enter the serial number of the concerned certificate or bond at this stage. After entering the serial number, all related information, including the related product, its nominal value, and etc. will be shown. The portal will match the serial number, username, and password and in case of controversy, will send an error message to the client. In case of no error, the client will be able to confirm and send his sale proposal. A copy of his proposal will be left in his outbox, and the product selection page will be updated automatically.

\footnotetext{
${ }^{14}$ Bidabad, Bijan, Abul Hassan, Ben Ali Mohamed Sami, Mahmoud Allahyarifard. Interest-Free Bonds and Central Banking Monetary Instruments. International Journal of Economics and Finance. Vol. 3, no. 3, August 2011, pp.234-241. http://www.ccsenet.org/journal/index.php/ijef/article/download/11665/8300
} 
- Buyer and Seller Connection: After the end of the allowed sale duration (one day as a predefined period), the portal will disable the possibility of offering a new proposal for the item in question. The system will consider the latest (highest) offered the proposal as its price and settle the purchaser's account equal to this amount plus its commission ( 0.5 per thousand of total value) from his account that had been blocked before. Before settlement of seller's account, the commission will be deducted. The portal will automatically change the ownership of the certificate or bond from the seller to the buyer and send the bill to the inbox of seller and buyer and updates the product selection database.

- Registration and Inquiry: If buyer and seller do not want to go through buy/purchase page of the portal and want to contract by mutual agreement for transacting certificates or bonds, they have to register the activity in the registration section of the portal. The seller will enter his username and password and after confirming the concerning conditions and regulations (including commission involved), will enter the serial number of his asset. This number will be matched by other related information, and if they do not match, the transaction will be stopped. Then, username and password of the buyer will be entered, and his information will be displayed. If his identity specification is correct, the seller will confirm the activity. Then, the bank will deduct 0.5 per thousand as a commission (according to the latest transaction price of a similar product) from the accounts of transaction sides, and changes the ownership of certificate/bond and updates the database.

- Settlement: At the end, the profit/loss of the last holder of certificate/bond will be calculated and settled with the client's account, and he will be informed. In case of loss, the amount of loss will be deducted from the nominal value of the latest certificate/bondholder, and he will receive a bill. After settlement, the transaction of the concerned certificate/bond will be disabled until the final condition of the project is obtained. After the settlement of clients' accounts, the serial numbers of the concerned project will be disabled, and databases of the market and branches will be updated. Those settled serial numbers will also be dropped from the client's profile.

5. Operational and Technical Instruction of Rastin Certificate Market (RCM)

Article (1) Transaction definitions:

- The latest transaction day: the latest day in which transaction of a certificate/bond is possible in Rastin Certificate Market.

- Value of contract: the value of undertaken products by the entrepreneur at the time of forming the contract.

- Certificate transaction notice: is the information released to inform buyers about the conditions and states of the concerned product.

- Delivery notice: is a notice offered to buyers by PLS department of the bank about the delivery of the product.

- Risk manifest: is a form to be signed by buyer before activity in the market and is about observing the risks involved in the transaction

- Delivery: is the delivery of the product of the matured certificate by the seller or entrepreneur according to the related contract.

- Ordinary transaction period: is a time period that transaction of certificate is done according to Rastin Certificate Market defined procedures.

- Customer's operational account: this is the client's (buyer, or seller) account used by the bank for settlement.

- Base asset: is the nominal value of the product of accepted certificates at maturity.

- Deadline of transaction: is the time at which transaction of certificate ends.

- Settlement date: is the time of settlement.

- Transaction duration: is defined as the time span between the starting and final date of transaction.

- Warehouse receipt: is a document issued by the warehouse that has been confirmed by PLS department of the bank and certifies the ownership of the bearer to a certain amount of commodity.

- Working day: is day and night hours of day and weekends and other holidays are not excluded.

- Order: is the purchase or sale order of buyer or seller that leads him to obligation conditions for purchasing or selling.

- Delivery readiness certificate: is the document through which the entrepreneur informs the bank about his readiness to deliver the commodity subject of the certificate.

- Market maker: is an intermediate or transactor delegated by the bank to transact Rastin Certificates at market price by considering financial regulations. 
Article (2) Bank is bound to establish RCM website with the following capabilities:

- Electronic payment through smart ATM cards (SHETAB members) and credible international cards such as VISA, MASTER, EXPRESS and AMERICAN cards (subject to accessibility to international cards gates).

- Support various exchanges.

- Support various languages.

- Connection to international ultra-bank integrated networks such as $\mathrm{SEPA}^{15}, \mathrm{SWIFT}^{16}$, and other transaction service providers such as PAYPAL and $\mathrm{API}^{17}$ (in case of agreement with the card issuer and money transfer service providers).

- Using $\mathrm{ACH}^{18}$ for small and $\mathrm{ARTGS}^{19}$ for large amounts.

- Using IBAN $^{20}$ international identification and other integrated identification methods.

- Electronic payment system.

- Connection to electronic money transfer systems such as RTGS ${ }^{21}$, ACH, Inter-Bank Information Exchange network (SHETAB), and ${ }^{\text {SSSS22 }}$.

- Connection to ${ }^{\mathrm{NSSSS} 23}$ of Central Bank.

- Electronic integrated registration and keeping information of papers holders, ownership transfer, issuance, selling and buying operations on certificates and negotiable papers in the database.

- Information system for available investment projects.

- Establishment of different electronic showcases for offering Rastin Certificates and Rastin Swap Bonds.

- Possibility to show the queues of buyers and sellers and price proposals.

- Providing selling and buying usury-free documents and certificates tenders based on competitive prices.

- Automatic repayment settlement after dropping from tender list and acceptance of higher bids.

- Integration with other internal and external financial systems and Core banking subsystems.

- International data transfer standards.

- Accounting and registering records operations, client's desk, record tracking, and workflow management, auditing, monitoring, controlling, and supervision.

- Report generating according to the needs of various management levels, experts, and clients.

- Business intelligence and comparison of expected profit, maturity, competency of the entrepreneur, and other quality characteristics that affect the risk and productivity of different papers.

- System risk management including liquidity, credit, operational and market risk management.

- Designing and offering units and baskets of certificates and bonds.

- Providing financial engineering tools and analytical services.

- Coding of certificates and financial documents according to prevailed international standards.

- Transaction relation capability with websites of Central Bank, other banks, and internal and international bourses and agents by concentrating information at Central Bank databases.

- Payment transfer insurance through systems such as FDIC ${ }^{24}$ and others.

- Mobile, telephone, and other communication support of transaction and payment.

- Webpages should be responsive to be automatically resized in different sizes of monitors and smartphones.

- Should possess the abilities to use Content Management Systems (CMS) and interconnection to social networks characteristics.

- Possibility of using Unstructured Supplementary Service Data (USSD) to prepare facilities for client payment phone communication operators.

- Possibility of using Near Field Communication (NFC) to prepare smartphone transaction operations.

Article (3) Bank and depositors can transact Rastin Certificates and Rastin Swap Bonds at Rastin Certificate Market $(\mathrm{RCM})$ at market prices or transfer by agreed prices.

Article (4) All transactions, transfers, and payments should be registered at the paper issuer bank's website so that

\footnotetext{
15 Single Euro Payment Area (SEPA)

${ }^{16}$ The Society For Worldwide Interbank Financial Telecommunication (SWIFT)

17 Arab Payments and Securities Settlement Initiative (API)

${ }_{19}^{18}$ Automated Clearing House

${ }^{19}$ Automated Real-Time Gross Settlement (ARTGS)

${ }^{20}$ International Bank Account Number (IBAN)

21 Real Time Gross settlement System (RTGS)

${ }^{22}$ ScripLess Security Settlement System (SSSS)

${ }^{23}$ Non-Usury ScripLess Security Settlement System (NSSSS)

${ }^{24}$ Federal Deposit Insurance Corporation (FDIC)
} 
can be traced in case of need.

Article (5) Entrepreneur, like other real and legal persons, can enter, transact, and transfer in Rastin Certificate Market.

Article (6) Bank can use of bourse agents and market-makers in connection to Rastin Certificate transactions. In this regard, the bank is bound to design its website in a way to force them using it. The detail of their transactions, similar to any other transactions, should be registered (Article 11) in the bank's database.

Article (7) Dealers and market-makers can cover the risk of Rastin Certificates by offering insurance companies services fully or partially.

Article (8) Bank is bound to establish primary and secondary markets of Rastin Certificates at its website.

Article (9) At the time of purchase and selling or transfer operations, before finalizing the proposal, a webpage opens on client's monitor showing the detail of the obligations involved in the operation and he must accept regarding conditions by click before obtaining transaction permission.

Article (10) Each Rastin Certificate presented at the primary market should have a unique serial number in the banking system.

Article (11) All Rastin Certificates and Bonds transaction activities and corresponding payment information should be registered at the bank's database. The information includes buyer's and seller's identities, bank card number, account number, national identity number for real persons and identity number for legal entities and all other identification information of the parties involved, serial numbers of transferred certificates and bonds, login system information of client at time of transaction and other similar information.

Article (12) By installing necessary security systems, the bank is bound to provide proper security for clients' operations. Security definition should be based on multi-factor authentication. Firewalls, account activity auditing, Virtual Private Network (IPsec VPN, SSL VPN), Intrusion Prevention System (IPS), Webguard, Syslog, Simple Network Management Protocol (SNMP), Computer Security Incident Response Team (CSIRT), Penetration Test, Network Security and Operation Center, standards and considerations of data security should be observed in bank's data network architecture.

Article (13) Bank is bound to consider more advanced security systems for large transactions. Definition of "large transaction" is done by the bank's management.

Article (14) By receiving client's account number and security codes, the bank should upload all other client's information at the webpage. By clicking the accept button, the client confirms the information.

Article (15) At each stage of the transaction, the client's identity and account numbers are the bases for verification. The bank is obliged to define a unique identification number for each client.

Article (16) By using unique international identification and account numbers, the bank is obliged to design its system in such a way that the client can interact internationally.

Article (17) Bank is bound to provide the possibility of managerial reporting for different accessing levels with different query parameters in its website.

Article (18) During any transaction and transfer of paper, all the details will be shown to buyer and sellers before finalizing transaction or transfer. Complete texts of the corresponding contracts and enclosures will be emailed to buyer's inbox at the end.

Article (19) Bank by signing up user accounts and establishing fan pages in usual social networks will publish necessary information and announcements of Rastin Certificate Market (RCM) webpages into the cited bank's user and fan pages in social networks automatically; till the depositors and social network users can access Rastin Certificate Market services through this facility.

Article (20) Bank for data entry and evaluation of project proposal and entrepreneur designs and installs necessary webpages in Rastin Certificate Market by observing the latest release of COMFAR software of UNIDO ${ }^{25}$. Entrepreneurs can enter their data and project proposal data according to COMFAR input fields. The cited webpages should be able to analyze the information of the project proposal according to the COMFAR output format.

Article (21) Main parts of Rastin Certificate Market portal include: informative, registration and membership, purchase and sale, primary and secondary markets, communication of buyer and seller, registration and inquiry, payment gate, managerial reporting, agreed transfer, follow-up and other necessary capabilities.

- The informative portal includes all information about projects and their conditions and progresses, and Rastin Certificate Market for the public. Balance sheet information, profit and loss sheet and the other financial report of Rastin PLS activities of the branch or bank are shown at this portal.

- Instruction for introducing to Rastin Certificate Market, the forming parts, entrance, and application

\footnotetext{
${ }^{25}$ United Nations Industrial Development Organization. http://www.unido.org/en/resources/publications/publications-by-type/software/comfar.html
} 
procedure in the market are described in the information portal. This section should be designed in a way that could answer the main clients' questions about Rastin PLS system.

- All clients should fill the specified forms (purchase, sale, and transfer) at registration portal according to the selected services. Those clients who want to use purchase and sell services, in addition to confirming their electronic signature and regulations concerning the electronic transaction of Rastin Certificates, should have opened a special account for this purpose with a sum equal to the value of the transaction plus its commission.

- After opening an acceptable e-account and filling the related forms in the system, each client will receive a unique application code. This code will be used for identification hereafter. After entering the website of Rastin Certificate Market of the bank, the client will enter registration and membership page and will enter his identification code and email address. Username and application code will be emailed to him.

- The buy/sell page is specified for proposing purchasing and selling proposals. For offering a proposal, the client should enter his username and application (user) code and after confirming regulations and commission concerning the transaction, will be allowed to enter into this section. The client can monitor the latest information concerning offered certificates for sale, including the kind of product related to certificates and the latest price proposal. If the client is inclined to buy a certificate, he can enter the purchasing portal, click that certificate, and include it in his purchasing basket. Then he has to offer his inclined price that should be higher than the latest price offered for that certificate; otherwise, his proposed price will not be registered.

- To stimulate the purchasing desire of clients, the bank can email information concerning the proposals (highest price and amount proposed) to all members of the website. The value of the client's purchase, plus a commission charged should not be more than the amount left in his specified account. If the value exceeds the value of his specified account, the client will receive a message to drop some items of his purchasing basket.

- After confirming and sending the proposal, the client will have a copy of his proposal in his inbox.

- The specified account of the client will be blocked for his purchase equal the bid amount until he has purchasing priority (highest proposed price). Product selection section of the e-market will be updated after receiving each new proposal. Blocking/unblocking activity of the client's account will be announced to him through email.

- In order to offer a purchase proposal, the client has to enter his username and application code (password) and after confirming concerned regulations, can enter to purchasing page of the portal. By filling forms for selling his certificates, his proposal will be enlisted among sellers list.

- Selling time span is predefined. In this case, this time is 24 working hours according to Tehran time zone. In other cases, the client can define a selling time span of up to 15 days.

- After the end of the time span, if the certificate is not sold, the client can offer a new selling time span. The seller cannot cancel his selling proposal before the end of each time span.

- It is necessary to enter a serial number of selling certificates at this stage. After entering the serial number, which is unique, other information such as the product related to the certificate, nominal value, and etc. will be displayed on the monitor. By matching the serial number with user application code, the application will send an error message if does not match, and he will not be able to sell the certificate.

- In the case of no error, the client can confirm his proposal. A copy of his proposal will be sent to his email, and the system will upgrade the database.

- At the buyer-seller communication part, the portal will disable the possibility of receiving a new proposal for the regarded certificate, and the latest price proposal will be considered as the purchasing price of the buyer. The total value of purchase, plus its commission ( 0.5 per thousand) will be deducted from the specified account of the buyer, which had been already blocked for this amount systematically and seller's share will be paid to his specified account. Bank's commission will be carried into the specified account of the bank.

- After transferring the sums, the software will transfer the ownership of the bought certificate to buyer systematically, and transaction bill will be sent to buyer and seller. Regarding the transaction, product selection page will be updated.

- Buyer and seller can transfer Rastin Certificate directly by going through registration and inquiry page. The portal will transfer the ownership and update its database.

- After entering his username and password at the registration page and confirming the involved regulation concerning electronic transaction of Rastin Certificate, commission, and electronic signature, the seller should enter his certificate serial numbers. By entering the serial number, all information about the 
certificate will be displayed, and the owner's name and other information will be checked. In case of mismatch, the seller cannot continue to transfer the ownership. Then, the buyer's username and password will be entered, and the portal will display his other characteristics. If the information were correct, the seller would confirm the transaction. The 0.5 per thousand commission of the bank will be calculated based on the latest price of the similar previously transacted certificates and will be systematically deducted from specified accounts of the seller and buyer and be carried to the specified account of the bank. Both sides should have specified the account to use RCM, and their account numbers will be displayed on the monitor, which should be confirmed by clients. After transferring money, the system will update the database of Rastin Certificate Market systematically.

Note: In case of absence of similar previous transaction record, the nominal value of the certificate will be the basis for the calculation of transfer commission of bank.

- If the client is inclined to have a printed copy of the transaction, it will be provided according to the Operational Bylaw of Rastin Banking.

- At the end of the project and calculating profit/loss, the share of depositors will be calculated proportional to their shares (deposits) and durations of deposits according to the chapter of Rastin PLS Accounting of Operational Bylaw of Rastin Banking about time-share and other related instructions. The calculated profit will be paid to the account of the latest certificate holder, and he will be informed through sending him a bill. In case of loss, the loss will be covered up to the ceiling of the nominal price of certificate by provided insurances.

Note: In exceptional cases, if the insurance coverage were not enough to compensate the loss, the difference will be deducted from the nominal value of the certificate and remainder will be paid to certificate holder's account. The client will be informed about this fact by sending him a bill.

- Before settlement, the clients of Rastin Certificate Market will be informed about the action. After starting the settlement process, the possibility of the transaction will be disabled until the end when the profit or loss condition has been determined.

- After carrying the profit to the client's specified account, or deducting the loss from his account, all settled Rastin Certificates will be systematically tagged, and the Rastin Certificate database will be updated. The serial numbers of settled certificates will be dropped from the owner's profile.

- Holders of endless projects certificates can transact these papers at Rastin Certificate Market before they are transformed into shares.

References

Rastin Banking documents are accessible at: http://www.bidabad.com

Bidabad, Bijan. (2014). New Operational Islamic Banking System, Volume One, Theoretical Foundations, LAP Lambert Academic Publishing, OmniScriptum GmbH \& Co. KG, ISBN: 978-3-659-54463-7.

Bidabad, Bijan. (2014). New Operational Islamic Banking System, Volume Two, Applicational Issues, LAP Lambert Academic Publishing, OmniScriptum GmbH \& Co. KG, ISBN: 978-3-659-55210-6.

Bidabad, Bijan (2018), General Regulatory Framework in Rastin Profit and Loss Sharing Banking (Part IOperational Context). Journal of Business and Finance in Emerging Markets, JBFEM, [S.1.], v. 1, n. 1, p. 1126, May. ISSN 2580-5568.

https://doi.org/10.32770/jbfem.vol111-26

http://www.bidabad.com/doc/rastin-regulatory-en-I.pdf

Bidabad, Bijan (2018), General Regulatory Framework in Rastin Profit and Loss Sharing Banking (Part II-Legal Groundwork). Journal of Business and Finance in Emerging Markets, JBFEM, JBFEM, [S.1.], v. 1, n. 2, p. 109-126, Nov. ISSN 2580-5568.

https://doi.org/10.32770/jbfem.vol1109-126

http://www.bidabad.com/doc/rastin-regulatory-en-II.pdf

Bidabad, Bijan (2019), General Regulatory Framework in Rastin Profit and Loss Sharing Banking (Part IIIAuxiliary Provisions). Journal of Business and Finance in Emerging Markets, JBFEM, May, Vol 2, No. 1, pp. 51-65. ISSN 2580-5568. https://doi.org/10.32770/jbfem.vol251-66 http://www.bidabad.com/doc/rastin-regulatory-en-III.pdf

Bidabad, Bijan, General Characteristics of Rastin Banking, 2013. 
http://www.bidabad.com/doc/rastin-bank-general-en.pdf

Bidabad, Bijan, Abul Hassan, Ben Ali Mohamed Sami, Mahmoud Allahyarifard (2011) Interest-Free Bonds and Central Banking Monetary Instruments. International Journal of Business and Management Science. Vol. 3, no. 3, August.

Bidabad, Bijan, Rastin Profit and Loss Sharing (PLS) Base System. Journal of Islamic Economics, Banking and Finance, pp. 32-57, Vol. 9 No. 4, Oct - Dec 2013. http://ibtra.com/pdf/journal/v9_n4_article2.pdf http://www.bidabad.com/doc/pls-base-en.pdf

Bidabad, Bijan, Joalah Finance Sharing (JFS). Journal of Islamic Economics, Banking and Finance, Volume-12, No. 1, January-March, 2016, pp. 33-48. http://www.bidabad.com/doc/jfs-paper-en.pdf http://ibtra.com/pdf/journal/v12_n1_article2.pdf

Bidabad, Bijan, Mudarebah Financial Sharing (MFS). Journal of Islamic Economics, Banking and Finance, JIEBF, Volume - 10, Number - 1, January - April 2014, pp. 56-68. http://www.bidabad.com/doc/mfs-paper-en.pdf http://ibtra.com/pdf/journal/v10_n1_article3.pdf

Bidabad, Bijan, Instalment Financial Sharing (IFS), 2011. http://www.bidabad.com/doc/ifs-paper-en.pdf

Bidabad, Bijan, Rent Financial Sharing (RFS). Journal of Islamic Economics, Banking and Finance, Vol. 10 No. 2, pp.: 38-53, April-June 2014. http://www.bidabad.com/doc/rfs-paper-en.pdf http://ibtra.com/pdf/journal/v10_n2_article2.pdf

Bidabad, Bijan, Bail Financial Sharing (BFS), 2012. http://www.bidabad.com/doc/bfs-paper-en.pdf

Bidabad, Bijan, Rastin Personal Security (RPS). Journal of Islamic Economics, Banking and Finance, JIEBF, Volume - 11, Number - 2, April - June 2015, pp. 47-61. http://www.bidabad.com/doc/rps-paper-en.pdf http://ibtra.com/pdf/journal/v11_n2_article3.pdf

Bidabad, Bijan, Rastin Social Takaful (RST). Journal of Islamic Economics, Banking and Finance, JIEBF, Volume 11, Number - 1, January - March 2015, pp.: 13-23. http://www.bidabad.com/doc/rst-paper-en.pdf http://ibtra.com/pdf/journal/v11_n1_article1.pdf

Bidabad, Bijan, Abul Hassan, Ben Ali Mohamed Sami, Mahmoud Allahyarifard. Interest-Free Bonds and Central Banking Monetary Instruments. International Journal of Economics and Finance. Vol. 3, no. 3, August 2011, pp.234-241. http://www.ccsenet.org/journal/index.php/ijef/article/download/11665/8300

http://uk.zopa.com/

http://pls.bmi.ir/

\section{Copyrights}

Copyright for this article is retained by the author(s), with first publication rights granted to the journal.

This is an open-access article distributed under the terms and conditions of the Creative Commons Attribution license (http://creativecommons.org/licenses/by/4.0/) 